\title{
The importance of topical metronidazole in the treatment of acute anal fissure: a double-blind study controlled for prospective randomization
}

\author{
Tuba Mert \\ Department of General Surgery, Pendik Medipol University School of Medicine, Istanbul, Turkey
}

Purpose: Acute anal fissure, a disease characterized by severe pain in the anorectal area, reduces quality of life and becomes chronic absent appropriate treatment. More recently, anaerobic infections have been noted as contributive to etiopathogenesis. This study investigates topical metronidazole's effect in the treatment of acute anal fissure.

Methods: Our prospective randomized controlled double-blind study included 2 groups of 100 patients older than 18 years from our General Surgery Clinic with anal fissure complaints for less than 8 weeks. Topical diltiazem treatment was started in group 1, and topical diltiazem and metronidazole treatment in group 2. Pain levels were evaluated by the visual analogue scale (VAS) score, and recovery status was evaluated by physical examination findings ab initio and at the 1st, 4 th, and 6th weeks. VAS score levels, demographic, clinical, and recovery status were then compared.

Results: There was no difference between the groups as to age, sex, pain on defecation, bleeding, constipation, and duration of pain, bleeding and constipation $(\mathrm{P}>0.05)$. From week 1, fissure epithelialization and healing rates were higher in group $2(\mathrm{P}<0.001)$; group 2 VAS score levels were lower than in group $1(\mathrm{P}<0.001)$ and achieved by group 1 only in week $4(\mathrm{P}=0.073)$.

Conclusion: Adding topical metronidazole to treatment reduces the duration and severity of pain, shortens healing time, and increases the healing rate.

\section{Keywords: Acute anal fissure; Anti-bacterial agents; Diltiazem; Metronidazole; Topical therapy}

\section{INTRODUCTION}

An anal fissure results from an elliptical or longitudinal tear in the squamous epithelial tissue distal to the dentate line and is usually located in the posterior midline of the anus. The disease, which causes severe pain in the anal area, impairs quality of life and can adversely impact work productivity $[1,2]$. The disease can be acute or chronic [3]. In an acute anal fissure, only the epithelial

Received: Jul 31, 2021 - Revised: Sep 9, 2021 - Accepted: Sep 14, 2021

Correspondence to: Tuba Mert, M.D.

Department of General Surgery, Pendik Medipol University School of Medicine, Bahçelievler, Adnan Menderes Bulvari No:31-33, Pendik, Istanbul 34893, Turkey

Tel: +90-216-682-8000, Fax: +90-216-912-22-23

E-mail:dr.tgulcelik@gmail.com

ORCID: https://orcid.org/0000-0002-4481-2161

(C) 2022 The Korean Society of Coloproctology

This is an open-access article distributed under the terms of the Creative Commons Attribution NonCommercial License (https://creativecommons.org/licenses/by-nc/4.0) which permits unrestricted noncommercial use, distribution, and reproduction in any medium, provided the original work is properly cited. tissue is ruptured, with pain in the anal region, with symptoms of defecation and bleeding lasting less than 2 months. In a chronic anal fissure, symptoms last longer than 6 to 8 weeks; in addition to the symptoms noted above, it is characterized by exposed fibers of the internal anal sphincter at the base of the fissure, hypertrophied anal papillae at the proximal end, and skin tags at the distal [4]. The disease affects both sexes equally in all age groups [5]. Most anal fissures are acute and resolve spontaneously or within 6 to 8 weeks of treatment [6]. Although its etiology is not known exactly, it is thought to be multifactorial and can be the result of spontaneous internal anal sphincter spasm, ischemia, infection, and local trauma [7]. In the treatment of acute anal fissure, conservative treatments such as a fiber-rich diet, regular toilet habits and warm sitz baths, muscle relaxants, and blood flow enhancing drugs such as diltiazem and anesthetic drugs are generally used [3, $8,9]$. Topical nitrates and botulinum toxin are not preferred because of the rapid disappearance of their effects and undesirable side effects [10]. Surgical lateral internal sphincterotomy is applied as the gold standard treatment in patients, who do not re- 
spond to medical treatments. However, surgical risks and the incidence of late persistent incontinence are important postoperative complications $[11,12]$.

In recent studies, it has been reported that there can be subclinical infection mostly due to the presence of anaerobic bacteria in the anal fissure region, and the use of topical or oral antibiotics in addition to conventional medical treatment increases wound healing and reduces pain $[7,13,14]$. In studies on this subject, the effect of local or systemic antibiotics was mostly performed on patients with chronic anal fissure.

In this study, our aim is to investigate whether the use of topical metronidazole, which is effective against anaerobic bacteria, which are claimed to cause subclinical infection in the anal fissure, in addition to diltiazem, a calcium channel blocker that has been used for years in the treatment of acute anal fissure, are superior to the use of diltiazem alone.

\section{METHODS}

A total of 100 patients admitted to the General Surgery Clinic of Istanbul Medipol University Faculty of Medicine Hospital (between December 2020 and May 2021) and diagnosed with acute anal fissure were included in our prospective randomized controlled double-blind study. The study was performed with the approval of the Clinical Research Ethics Committee of Faculty of Medicine, Istanbul Medipol University (November 11, 2020; No. 851). Informed consent was obtained from all patients.

Patients older than 18 years, with complaints of anal fissure for less than 8 weeks, anal fissure lesions limited to the epithelium on physical examination, and no findings suggestive of chronic anal fissure (such as skin tag in the anal region) were included in the study. Patients with perianal fistula and perianal abscess; with concomitant inflammatory bowel disease and immunodeficiency; taking oral immunosuppressants or steroids; with a history of hemorrhoidectomy; with chronic diseases such as ischemic heart disease, hypertension, or migraine; who were pregnant; and who were already treated with other topical creams were excluded from the study.

Patients were randomly divided into 2 groups of 50 people, with participants choosing color-coded cards in thick white envelopes. Patient medication was delivered by a doctor who saw the color of the cards and was not one of the coordinators of our study. All patients and all the investigators evaluating them were blinded to randomization. As a calcium channel blocker, only $2 \%$ diltiazem cream (Locafen 2\% cream; Ilko Ilac Sanayi ve Ticaret A.S., Istanbul, Turkey) was used for patients in group 1, and 2\% diltiazem cream and metronidazole cream (Rosa cream [1\% metronidazole]; ORVA Ilac Sanayi ve Ticaret A.S., Izmir, Turkey) were used for patients in group 2. Demographic characteristics of all patients were recorded, a detailed anamnesis was taken, and physical examination was performed before the start of treatment. Pain complaints during defecation were evaluated with the visual analogue scale (VAS) [15]. All patients were instructed to circulate each pea-sized drug 1-2 cm into the anus with the tip of the index finger 3 times a day for 6 weeks. They were also advised to eat a fiber-rich diet and take a 15-minute warm bath 3 times a day. No stool softener or topical analgesic cream was prescribed to the patients during the treatment. At the end of the 1st, 4 th, and 6 th weeks of treatment, the patients were called for control visits and examined, and their VAS scores were recorded.

The effectiveness of the treatment was evaluated according to the level of healing of the fissure and the severity of the pain. The fissure was visually inspected and evaluated at each visit, while the degree of epithelization was determined as follows: 0 , no epithelialization in the fissure; 1 , there is epithelialization in the fissure; and 2 , the fissure is fully healed. The VAS score was used to measure pain after defecation. The scale is divided into 10 equal parts; 0 indicated no pain and 10 indicated unbearable pain. Clinical improvement was considered as complete reepithelialization of the anal canal mucosa and closure of the fissure without erythema or inflammation and relief of patient complaints.

\section{Statistical analyses}

IBM SPSS Statistics ver. 26.0 (IBM Corp., Armonk, NY, USA) was used in the analysis of the variables. The conformity of univariate data to normal distribution was evaluated with the Shapiro-Wilk Francia test. The Mann-Whitney U-test was used together with Monte Carlo results to compare 2 independent groups with each other according to quantitative data. While Friedman 2-way test was used to compare the measurements of dependent quantitative variables with more than 2 replicates with each other, Monte Carlo simulation results were used, and the stepwise stepdown comparisons test was used for the post hoc test. The McNemarBowker test was used with the Monte Carlo simulation technique to compare the variables with 2 dependent categories. In the comparison of categorical variables with each other, the Pearson chisquare and Fisher exact tests were used with the Monte Carlo simulation technique, and column ratios were compared with each other and expressed according to Benjamini-Hochberg corrected P-value results. Quantitative variables were expressed as medians (interquartile ranges, IQRs) in the tables, while categorical variables were shown as numbers (\%). Variables were analyzed at a $95 \%$ confidence level, and $\mathrm{P}<0.05$ was considered to be significant.

\section{RESULTS}

Of the 100 patients included in the study, 90 were female and 10 were male. The median (IQR) age of the patients in group 1 was 32.5 years ( $28-48$ years); and in group 2, it was 32 years (25-45 years). Forty-six patients (92.0\%) in group 1 and $44(88.0 \%)$ in group 2 were female. Pain symptoms were present in defecation in all patients in both groups. Constipation and bleeding during defecation were detected in $44(88.0 \%)$ and 43 patients $(86.0 \%)$ in 
group 1, and in $44(88.0 \%)$ and 38 patients $(76.0 \%)$ in group 2, respectively. The medians (IQRs) of the duration of pain, bleeding time, and constipation duration of the patients were detected to be 4 weeks (2-4 weeks), 4 weeks ( $2-4$ weeks), and 4 weeks (3-5.5 weeks) in group 1, and 3 weeks ( $2-4$ weeks), 3 weeks ( $2-4$ weeks), and 4 weeks (4-8 weeks) in group 2 , respectively. There was no statistical difference between group 1 and group 2 in terms of age, sex, pain at defecation, presence of bleeding, presence of constipation, duration of pain, duration of bleeding, and duration of constipation $(\mathrm{P}>0.05)$ (Table 1).

At the end of the 4th week, only 4 patients (8.0\%) in group 1 had complete recovery; while in group 2, 12 patients $(24.0 \%)$ had complete recovery. At the end of the 6th week, 21 patients (42.0\%) in group 1 and 41 patients (82.0\%) in group 2 had fully recovered. When the groups were compared in terms of physical examination findings and recovery rates, it was found that both epithelization and the healing rates of the patients in group 2 were statistically significantly higher than those in group 1 from the 1st week $(\mathrm{P}<0.001)$ (Fig. 1 and Table 2).

The median (IQR) VAS score levels were found to be $8(6-8)$ in group 1 and 8 (7-9) in group 2, respectively, on the day of enrollment. At the end of the 1st week of treatment, the median (IQR) VAS score decreased from 8 to 5 (4-7) in group 2, while it decreased from 8 to $2(1-2)$ in group 2 . At the end of the 1st week, $25.0 \%$ of the patients in group 1 still had a VAS score above 7 . At the end of the 4th week, while the VAS score decreased from a median of 8 to 3.5 (IQR, 2-5) in group 1, the VAS score had de- creased from a median of 8 to 0 (IQR, $0-1)$ in group 2 . At the end of the 4th week, the VAS score was still above 5 in $25.0 \%$ of the patients in group 1 . When the groups were compared in terms of VAS scores detected on the day of enrollment and follow-up, it was found that the VAS scores of the patients in group 2 decreased much more rapidly after the 1st week, in line with the physical examination findings $(\mathrm{P}<0.001)$. In group 2 , the VAS score started to decrease rapidly from the 1st week and there were almost no patients with pain in the 4th week. The VAS scores of the patients in group 1 decreased at a slower rate and at the end of the 4th week, it was found that group 2 could only reach the VAS score level that group 1 reached in the 1 st week $(\mathrm{P}=0.073)$ (Fig. 2 and Table 3).

\section{DISCUSSION}

In our study, it was shown that the use of diltiazem and topical metronidazole for the treatment of acute anal fissure, compared to the use of topical diltiazem alone, reduced the severity of pain in a very short period of time and both shortened the healing time of the fissure and increased the healing rate.

Acute anal fissure affects both men and women equally [5]. We think that the reason for the higher number of female patients in our study was due to the fact that the surgeon who performed the anal examination and treatment of patients was female. Due to sociocultural reasons, especially in some regions of our country, female patients prefer female surgeons for perianal and genital ex-

Table 1. Comparison of the general characteristics of the patients included in the study according to the groups

\begin{tabular}{|c|c|c|c|c|}
\hline Characteristic & Total $(n=100)$ & Group $1(n=50)$ & Group $2(n=50)$ & P-value \\
\hline Age & $32(28-47)$ & $32.5(28-48)$ & $32(25-45)$ & $0.627^{\mathrm{a}}$ \\
\hline Sex & & & & $0.741^{b}$ \\
\hline Female & $90(90.0)$ & $46(92.0)$ & $44(88.0)$ & \\
\hline Male & $10(10.0)$ & $4(8.0)$ & $6(12.0)$ & \\
\hline Pain on defecation & & & & NA \\
\hline No & $0(0)$ & $0(0)$ & $0(0)$ & \\
\hline Yes & $100(100)$ & $50(100)$ & $50(100)$ & \\
\hline Bleeding on defecation & & & & $0.308^{c}$ \\
\hline No & $19(19.0)$ & $7(14.0)$ & $12(24.0)$ & \\
\hline Yes & $81(81.0)$ & $43(86.0)$ & $38(76.0)$ & \\
\hline Defecation difficulty & & & & $0.999^{c}$ \\
\hline No & $12(12.0)$ & $6(12.0)$ & $6(12.0)$ & \\
\hline Yes & $88(88.0)$ & $44(88.0)$ & $44(88.0)$ & \\
\hline Pain duration (wk) & $3.5(2-4)$ & $4(2-4)$ & $3(2-4)$ & $0.059^{\mathrm{a}}$ \\
\hline Bleeding duration (wk) & $4(2-4)$ & $4(2-4)$ & $3(2-4)$ & $0.069^{\mathrm{a}}$ \\
\hline Constipation duration (wk) & $4(3-7)$ & $4(3-5.50)$ & $4(4-8)$ & $0.450^{\mathrm{a}}$ \\
\hline
\end{tabular}

Values are presented as median (interquartile range) or number (\%).

NA, not applicable.

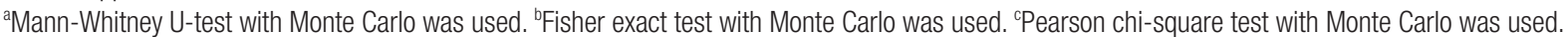




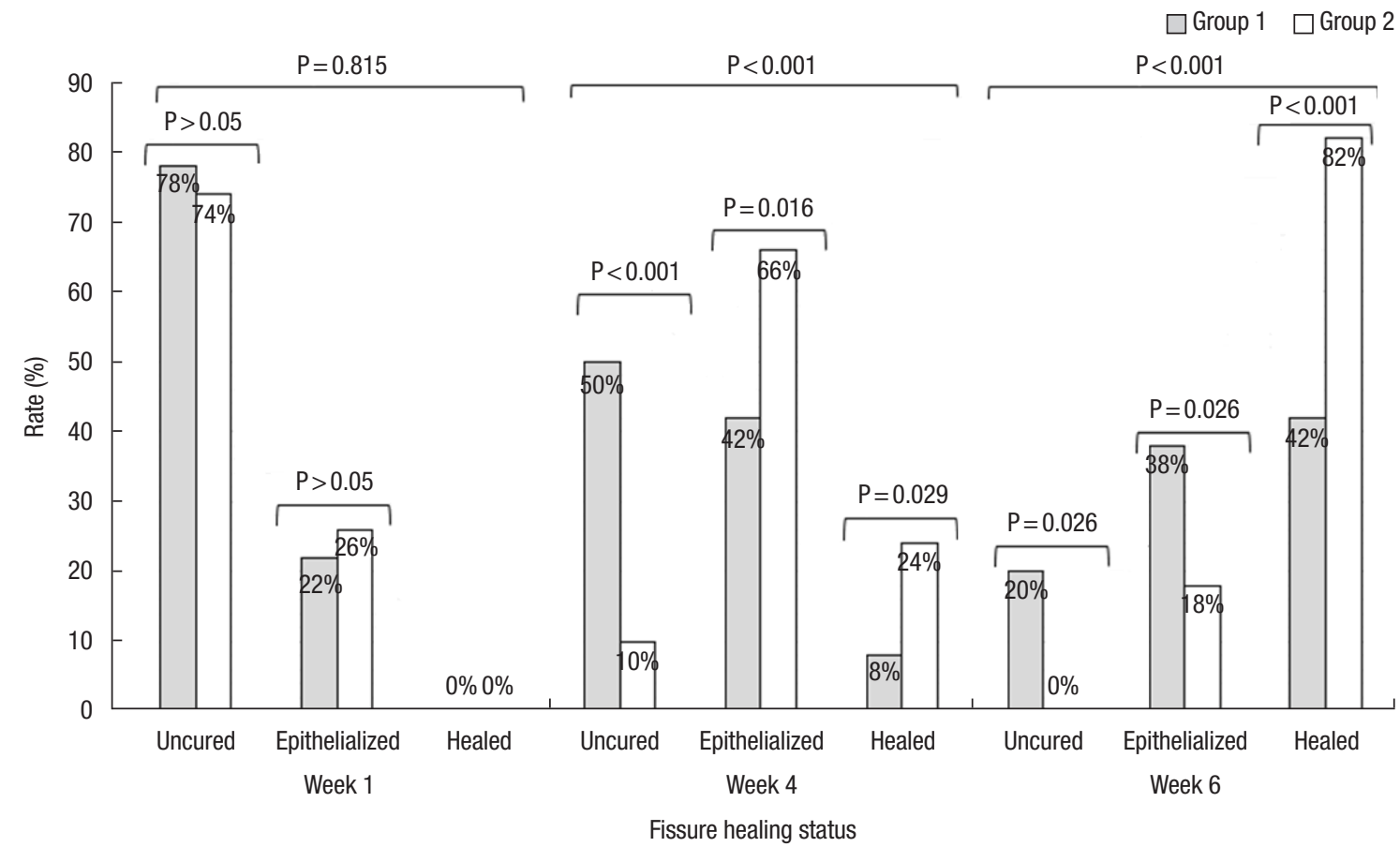

Fig. 1. Both the rate of epithelialization in the anal fissure and the rate of healing were found to be statistically higher in patients in group 2 , in which topical metronidazole was added to conventional treatment from the 1st week of treatment, compared to the rates for patients in group 1 , who received only conventional treatment $(\mathrm{P}<0.001)$.

Table 2. Comparison of treatment groups according to acute anal fissure healing status at 1-, 4- and 6-week of treatment

\begin{tabular}{|c|c|c|c|c|}
\hline Variable & Total $(n=100)$ & Group $1(n=50)$ & Group $2(n=50)$ & P-value \\
\hline Week 1 & & & & $0.815^{b}$ \\
\hline Uncured & $76(76.0)$ & $39(78.0)$ & $37(74.0)$ & \\
\hline Epithelialized & $24(24.0)$ & $11(22.0)$ & $13(26.0)$ & \\
\hline Healed & $0(0)$ & $0(0)$ & $0(0)$ & \\
\hline Week 4 & & & & $<0.001^{\mathrm{b}}$ \\
\hline Uncured & $30(30.0)$ & $25(50.0)^{c}$ & $5(10.0)$ & $<0.001$ \\
\hline Epithelialized & $54(54.0)$ & $21(42.0)$ & $33(66.0)^{d}$ & 0.016 \\
\hline Healed & $16(16.0)$ & $4(8.0)$ & $12(24.0)^{d}$ & 0.029 \\
\hline Week 6 & & & & $<0.001^{\mathrm{b}}$ \\
\hline Uncured & $10(10.0)$ & $10(20.0)^{c}$ & $0(0)$ & 0.026 \\
\hline Epithelialized & $28(28.0)$ & $19(38.0)^{c}$ & $9(18.0)$ & 0.026 \\
\hline Healed & $62(62.0)$ & $21(42.0)$ & $41(82.0)^{d}$ & $<0.001$ \\
\hline P-value for intra groups & & $<0.001^{e}$ & $<0.001^{e}$ & \\
\hline \multicolumn{5}{|l|}{ Pairwise comparison } \\
\hline Week 1 and 4 & & $<0.001$ & $<0.001$ & \\
\hline Week 1 and 6 & & $<0.001$ & $<0.001$ & \\
\hline Week 4 and 6 & & $<0.001$ & $<0.001$ & \\
\hline
\end{tabular}

Values are presented as number (\%).

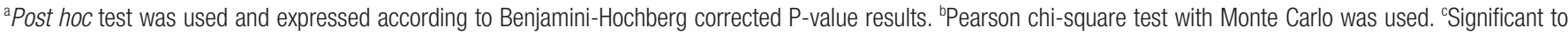
group 2. ${ }^{\circledR}$ Significant to group 1. ${ }^{\mathrm{e}} \mathrm{McNemar-Bowker}$ test was used. 
Table 3. Comparison of pain level between treatment groups according to VAS score

\begin{tabular}{|c|c|c|c|c|}
\hline Variable & Total $(n=100)$ & Group $1(n=50)$ & Group $2(n=50)$ & P-value ${ }^{a}$ \\
\hline \multicolumn{5}{|l|}{ VAS } \\
\hline Week 0 & $8(7-9)$ & $8(6-8)$ & $8(7-9)$ & 0.100 \\
\hline Week 1 & $3(2-5)$ & $5(4-7)$ & $2(1-2)$ & $<0.001$ \\
\hline Week 4 & $1(0-3.50)$ & $3.5(2-5)$ & $0(0-1)$ & $<0.001$ \\
\hline Week 6 & $0(0-2)$ & $2(1-3)$ & $0(0-0)$ & $<0.001$ \\
\hline \multicolumn{5}{|l|}{ Difference of VAS } \\
\hline Week 1 and 0 & $-5(-6$ to -2$)$ & $-2(-3$ to -1$)$ & $-6(-7$ to -6$)$ & $<0.001$ \\
\hline Week 4 and 0 & $-5.5(-8$ to -4$)$ & $-4(-4$ to -3$)$ & $-8(-8$ to -7$)$ & $<0.001$ \\
\hline Week 6 and 0 & $-6(-8$ to -5$)$ & $-5(-6$ to -5$)$ & $-8(-9$ to -7$)$ & $<0.001$ \\
\hline Week 4 and 1 & $-2(-2$ to -1$)$ & $-2(-2$ to -1$)$ & $-1(-2$ to -1$)$ & 0.073 \\
\hline Week 6 and 1 & $-2(-3$ to -1$)$ & $-3(-4$ to -2$)$ & $-2(-2$ to -1$)$ & $<0.001$ \\
\hline Week 6 and 4 & $-1(-1$ to 0$)$ & $-1(-2$ to -1$)$ & $0(-1$ to 0$)$ & $<0.001$ \\
\hline P-value for intra groups & & $<0.001^{\mathrm{b}}$ & $<0.001^{\mathrm{b}}$ & \\
\hline \multicolumn{5}{|l|}{ Pairwise comparison ${ }^{c}$} \\
\hline Week 0 and 1 & & 0.001 & $<0.001$ & \\
\hline Week 0 and 4 & & $<0.001$ & $<0.001$ & \\
\hline Week 0 and 6 & & $<0.001$ & $<0.001$ & \\
\hline Week 1 and 4 & & 0.001 & $<0.001$ & \\
\hline Week 1 and 6 & & $<0.001$ & $<0.001$ & \\
\hline Week 4 and 6 & & 0.006 & 0.999 & \\
\hline
\end{tabular}

Values are presented as median (interquartile range).

VAS, visual analogue scale.

aMann-Whitney U-test with Monte Carlo was used. ${ }^{\text {b} F r i e d m a n ~ t e s t ~ w i t h ~ M o n t e ~ C a r l o ~ w a s ~ u s e d . ~ ' S t e p w i s e ~ s t e p d o w n ~ c o m p a r i s o n s ~ w e r e ~ u s e d ~ f o r ~ t h e ~ p o s t ~ h o c ~ t e s t . ~}$

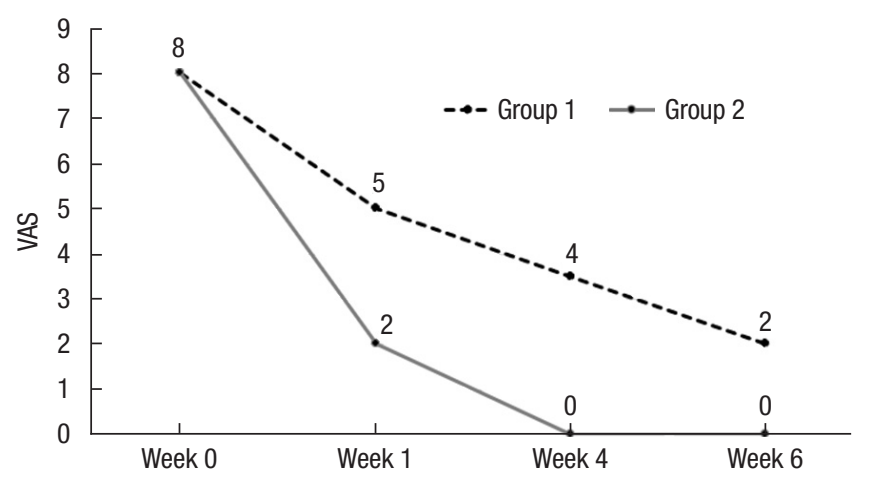

Fig. 2. From the moment the acute anal fissure treatment was started, the pain level (according to the visual analogue scale [VAS] score) of patients in group 2, who added topical metronidazole to conventional treatment, gave evidence of a rapid decrease compared to the pain level of patients in group $1(\mathrm{P}<0.01)$. The patients in group 1 could only achieve a similar VAS score in the 4 th week $(\mathrm{P}>0.073)$.

aminations.

Typical presenting symptoms in acute anal fissure are pain on defecation and bleeding. Pain is usually sharp and aggravated during defecation, sometimes painful defecation may be accom- panied by bleeding [16]. Similar to the literature, all of our patients had complaints of pain at defecation, and pain scores were found to be very high before starting treatment. In addition, defecation was accompanied by bleeding in $81.0 \%$ of the patients.

Spasm is known to occur in the internal anal sphincter in acute anal fissure [17]. Warm sitz baths contribute to the relaxation of the internal anal sphincter and the healing of the anal fissure through the somatoanal reflex [18]. Approximately half of acute anal fissures have been reported in studies to heal with only warm sitz baths and fiber diet intake [19]. In studies on etiology, due to the inadequate response of some patients to treatment, it has been shown that the bacteria found in the anal fissure area in $90 \%$ of patients with chronic anal fissure do not match the bacteria found in the stool flora of the same patients, Escherichia coli was reported to be one of the main causes [14]. In light of these data, in a study involving the topical application of povidone-iodine solution in chronic anal fissure, it was revealed that it contributed positively to the treatment. In the following years, in another study by the same authors, it was reported that chronic anal fissure could be treated with topical or systemic antibiotic treatment by preventing constipation [14]. In a study of Grekova et al. [13], of chronic anal fissure, after 4 weeks of conventional treatment, a $71 \%$ improvement was found in the control group, while com- 
plete recovery was achieved in $95.6 \%$ of the patient group in which topical metronidazole was added to the conventional treatment. Unlike previous studies, Karapolat [7] reported that a 44\% improvement was found in the control group with 4 weeks of topical lidocaine treatment in acute anal fissure, while an improvement of $86 \%$ was achieved in the group that added topical metronidazole to topical lidocaine treatment. In our study, similar to the literature, complete recovery was achieved in $42.0 \%$ of patients in the 6th week of treatment, using only topical diltiazem, while complete recovery was achieved in $82.0 \%$ of patients using topical diltiazem and metronidazole. In addition, it was shown that the increase in the rate of complete recovery started from the 1st week of treatment compared to that in the control group.

Alvandipour et al. [20] reported that the mean VAS score level of the patients, who had received topical diltiazem treatment in the treatment of chronic anal fissure was $3.2 \pm 0.25$ at the beginning of the treatment, and the VAS score level was reduced to $2.32 \pm 0.32$ at the end of 1 month of treatment. On the other hand, in a study by Martellucci et al. [21], evaluating patients with acute anal fissure, the median VAS score was 7.1 (range, 2-10) at the beginning of the treatment, and 1.7 at the end of 1 month of treatment. In a retrospective study of patients with acute anal fissure, Emile et al. [22] reported that the mean VAS score level was $8.8 \pm 0.96$ before treatment, and the mean VAS score level was $0.47 \pm 0.8$ after 6 weeks of treatment. Unlike the above studies, in patients with chronic anal fissure, Grekova et al. [13] reported that the VAS score level decreased in a shorter period of time from the day the treatment was started in the patient group using topical metronidazole compared to the period required for a similar decrease in the non-user group. Carrying out similar treatment in patients with acute anal fissure, Karapolat [7] reported that the VAS score levels of patients, who had received topical metronidazole treatment was significantly lower at the 2nd and 4th weeks of treatment compared to those of the patient group, who did not receive topical metronidazole treatment. In our study, similar to the literature, it was found that the VAS score level had decreased further in the patient group using topical metronidazole from the 1st week of treatment compared to the level of decrease in the group using diltiazem alone. In addition, in our study, it was shown that the VAS score level attained by the patient group using topical metronidazole in the 1st week of treatment was only achieved in the 4 th week by the group using diltiazem alone.

Our study has several limitations. First, the long-term recurrence rates are unknown due to the short follow-up period. The second limitation is that most of the patients included in the study were female. Despite these limitations, we think that our study contributes to the treatment of acute anal fissure in the adult age group.

In conclusion, with the addition of topical metronidazole to conventional treatment, the reduction of acute anal fissure-related pain in a short period of time, the shortening of the healing time of the fissure, and the high rate of healing indicate that infection plays an important role in the etiology of anal fissure. The use of topical metronidazole as an adjunct to conventional treatment may result in lower chronicity of acute anal fissures and avoidance of surgical interventions with high complication rates. We think that there is a need for new studies in which different topical antibiotic therapy options are employed.

\section{CONFLICT OF INTEREST}

No potential conflict of interest relevant to this article was reported.

\section{REFERENCES}

1. Hadianamrei R. Topical diltiazem in management of chronic anal fissure: a review of the literature. Clin Investig (Lond) 2014;4:92334.

2. Motie MR, Hashemi P. Chronic anal fissure: a comparative study of medical treatment versus surgical sphincterotomy. Acta Med Iran 2016;54:437-40.

3. Garg P, Lakhtaria P, Gupta V. Oral plus local antibiotics significantly reduce the need for operative intervention in chronic anal fissure: a novel finding. Indian J Surg 2018;80:415-20.

4. Salem AE, Mohamed EA, Elghadban HM, Abdelghani GM. Potential combination topical therapy of anal fissure: development, evaluation, and clinical study. Drug Deliv 2018;25:1672-82.

5. Collins EE, Lund JN. A review of chronic anal fissure management. Tech Coloproctol 2007;11:209-23.

6. Medhi B, Prakash A, Upadhyay S, Xess D, Yadav TD, Kaman L. Comparison of observational and controlled clinical trials of diltiazem in the treatment of chronic anal fissure. Indian J Surg 2011; 73:427-31.

7. Karapolat B. Could local antibiotics be included in the treatment of acute anal fissure? Turk J Surg 2018;34:286-9.

8. Perrotti P, Bove A, Antropoli C, Molino D, Antropoli M, Balzano A, et al. Topical nifedipine with lidocaine ointment vs. active control for treatment of chronic anal fissure: results of a prospective, randomized, double-blind study. Dis Colon Rectum 2002;45:1468-75.

9. Jonas M, Scholefield JH. Anal fissure. Gastroenterol Clin North Am 2001;30:167-81.

10. Bulus H, Varol N, Tas A, Coskun A. Comparison of topical isosorbide mononitrate, topical diltiazem, and their combination in the treatment of chronic anal fissure. Asian J Surg 2013;36:165-9.

11. Haq Z, Rahman M, Chowdhury RA, Baten MA, Khatun M. Chemical sphincterotomy: first line of treatment for chronic anal fissure. Mymensingh Med J 2005;14:88-90.

12. Yakoot M, Abdel Salaam M. Study of efficacy and safety of a new local cream ('healer') in the treatment of chronic anal fissure: a prospective, randomized, single-blind, comparative study. Arq Gastroenterol 2009;46:179-82.

13. Grekova NM, Maleva EA, Lebedeva Y, Bordunovsky VN, Tele- 
sheva LF, Bychkovskikh VA. The effects of topical application of metronidazole for treatment of chronic anal fissure: a randomized, controlled pilot study. Indian J Gastroenterol 2015;34:152-7.

14. Garg P. Local and Oral Antibiotics with Avoidance of Constipation (LOABAC) treatment for anal fissure: a new concept in conservative management. Indian J Surg 2016;78:80.

15. Hjermstad MJ, Fayers PM, Haugen DF, Caraceni A, Hanks GW, Loge $\mathrm{JH}$, et al. Studies comparing numerical rating scales, verbal rating scales, and visual analogue scales for assessment of pain intensity in adults: a systematic literature review. J Pain Symptom Manage 2011; 41:1073-93.

16. Qureshi W. How I approach it: anal fissures. Am J Gastroenterol 2020;115:315-6.

17. Farid M, El Nakeeb A, Youssef M, Omar W, Fouda E, Youssef T, et al. Idiopathic hypertensive anal canal: a place of internal sphincterotomy. J Gastrointest Surg 2009;13:1607-13.
18. Jiang JK, Chiu JH, Lin JK. Local thermal stimulation relaxes hypertonic anal sphincter: evidence of somatoanal reflex. Dis Colon Rectum 1999;42:1152-9.

19. Zaghiyan KN, Fleshner P. Anal fissure. Clin Colon Rectal Surg 2011;24:22-30.

20. Alvandipour M, Ala S, Khalvati M, Yazdanicharati J, Koulaeinejad N. Topical minoxidil versus topical diltiazem for chemical sphincterotomy of chronic anal fissure: a prospective, randomized, double-blind, clinical trial. World J Surg 2018;42:2252-8.

21. Martellucci J, Rossi G, Corsale I, Carrieri P, D’Elia M, Giani I. Myoxinol ointment for the treatment of acute fissure. Updates Surg 2017;69:499-503.

22. Emile SH, Elgendy H, Elfeki H, Magdy A, Abdelmawla AA, Abdelnaby $\mathrm{M}$, et al. Does the duration of symptoms of anal fissure impact its response to conservative treatment?: a prospective cohort study. Int J Surg 2017;44:64-70. 